\title{
Sitagliptin protects rat kidneys from acute ischemia- reperfusion injury via upregulation of GLP-1 and GLP-1 receptors
}

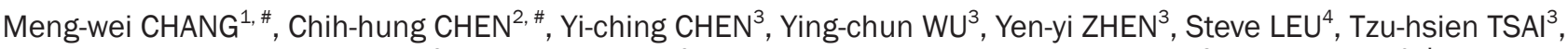 \\ Sheung-fat $\mathrm{KO}^{5}$, Pei-hsun SUNG ${ }^{3}$, Chih-chau YANG ${ }^{6}$, Hsin-ju CHIANG ${ }^{7}$, Hsueh-wen $\mathrm{CHANG}^{8}$, Yen-ta $\mathrm{CHEN}^{9, *}$, \\ Hon-kan YIP ${ }^{3,4, *}$ \\ ${ }^{1}$ Department of Emergency Medicine; ${ }^{2}$ Divisions of General Medicine; ${ }^{3}$ Division of Cardiology, Department of Internal Medicine; \\ ${ }^{4}$ Center for Translational Research in Biomedical Sciences; ${ }^{5}$ Department of Radiology; ${ }^{6}$ Division of Nephrology, Department of Internal \\ Medicine; ${ }^{7}$ Department of Obstetrics and Gynecology; ${ }^{9}$ Division of Urology, Department of Surgery, Kaohsiung Chang Gung Memorial \\ Hospital and Chang Gung University College of Medicine, Kaohsiung, Taiwan, China; ${ }^{8}$ Department of Biological Sciences, National Sun \\ Yat-Sen University, Kaohsiung, Taiwan, China
}

Aim: Sitagliptin, an oral glucose-lowering agent, has been found to produce cardiovascular protection possibly via anti-inflammatory and anti-atherosclerotic activities of glucagon-like peptide-1 receptor (GLP-1). The aim of this study was to investigate whether sitagliptin protected the kidney function from acute ischemia-reperfusion (IR) injury in rats.

Methods: Adult male SD rats were categorized into 4 groups: sham control, IR injury, IR+sitagliptin (300 mg/kg) and IR+sitagliptin (600 $\mathrm{mg} / \mathrm{kg})$. Acute renal IR injury of both kidneys was induced by clamping the renal pedicles for $1 \mathrm{~h}$. The drug was orally administered at 1, 24 and $48 \mathrm{~h}$ after acute IR. Blood samples and 24-h urine were collected before and at $72 \mathrm{~h}$ after acute IR. Then the rats were sacrificed, and the kidneys were harvested for biochemical and immunohistochemical studies.

Results: Acute IR procedure markedly increased serum levels of creatinine and BUN and the ratio of urine protein to creatinine. The kidney injury score, inflammatory biomarkers (MMP-9, TNF- $\alpha$ and NF-kB) levels and CD68+ cells in IR kidneys were considerably increased. The expression of oxidized protein, reactive oxygen species (NOX-1, NOX-2) and apoptosis proteins (Bax, caspase-3, PARP) in IR kidneys was also significantly upregulated. All these pathological changes were suppressed by sitagliptin in a dose-dependent manner. Furthermore, the serum GLP-1 level, and the expression of GLP-1 receptor, anti-oxidant biomarkers (HO-1 and NQO-1 cells, as well as SOD-1, NQO-1 and HO-1 proteins), and angiogenesis markers (SDF-1 $\alpha+$ and CXCR4+ cells) in IR kidneys were significantly increased, and further upregulated by sitagliptin.

Conclusion: Sitagliptin dose-dependently protects rat kidneys from acute IR injury via upregulation of serum GLP-1 and GLP-1 receptor expression in kidneys.

Keywords: sitagliptin; chronic kidney disease; ischemia reperfusion injury; inflammation; oxidative stress; reactive oxygen species; apoptosis; angiogenesis; GLP-1

Acta Pharmacologica Sinica (2015) 36: 119-130; doi: 10.1038/aps.2014.98; published online 15 Dec 2014

\section{Introduction}

End-stage renal disease (ESRD) is one of the most common life-threatening diseases. Despite the availability of state-ofthe-art treatment, the incidence of ESRD is still growing worldwide every year ${ }^{[1-3]}$. ESRD increases economic burden ${ }^{[4,5]}$

\footnotetext{
\# These authors contributed equally to this article.

* To whom correspondence should be addressed.

E-mail han.gung@msa.hinet.net (Hon-kan YIP); yenta1965@yahoo.com.tw (Yen-ta CHEN)

Received 2014-05-08 Accepted 2014-08-26
}

and is a leading cause of morbidity and mortality worldwide even with the availability of renal replacement therapy ${ }^{[6,7]}$. It is well known that chronic kidney disease (CKD) is the major cause of ESRD ${ }^{[8]}$. CKD is caused by divergent disease entities. Acute kidney injury (AKI) which is evident in around $20 \%$ of patients who die in hospitals and up to $50 \%$ of patients in intensive care units ${ }^{[9,10]}$, is one of the most common contributors to CKD. Among the various etiologies of hospital-acquired AKI, ischemia-reperfusion (IR) injury is the leading cause of $\mathrm{AKI}^{[11-13]}$ and is associated with high mortality $^{[14,15]}$. Surprisingly, although the epidemiology, etiologies, 
mechanisms, classification, and prognostic outcomes of acute IR kidney injury have been widely investigated for several decades ${ }^{[16-18]}$, there are still no effective therapeutic strategies for this condition other than supportive treatment. Accordingly, the development of new treatment modalities for acute IR kidney injury is needed ${ }^{[19]}$.

Prior to designing a safe and effective treatment, it is important to understand the underlying mechanisms that are involved in acute IR injury. Many previous studies have reported that the mechanisms underlying IR injuries in solid organs are multifaceted and involve the generation of reactive oxygen species $(\mathrm{ROS})^{[20-22]}$, oxidative stress ${ }^{[20-22]}$, mitochondrial damage ${ }^{[20-22]}$, apoptosis ${ }^{[19,22]}$, and a cascade of inflammatory processes $^{[22,23]}$.

Interestingly, sitagliptin, an oral glucose-lowering agent currently used for treating type 2 diabetes, has been found to enhance circulating glucagon-like peptide-1 (GLP-1) levels through inhibition of dipeptidyl peptidase IV (DPP-IV) activity ${ }^{[24,25]}$ which, in turn, provides cardiovascular protection probably through the anti-inflammatory and anti-atherosclerotic activities of GLP-1 ${ }^{[26]}$. Additionally, our study recently demonstrated that sitagliptin therapy enhances stromal cell-derived factor (SDF)-1a level, numbers of endothelial progenitor cells (EPCs) in circulation, and angiogenesis through inhibition of DDP-IV in CD26 cells ${ }^{[27]}$. Thus, it may be hypothesized that the inflammatory reaction and oxidative stress resulting from acute renal IR injury might be alleviated by sitagliptin treatment. This study further tested whether sitagliptin therapy augmented the expression of EPCs and angiogenesis factors in kidney parenchyma in the setting of acute IR injury.

\section{Materials and methods}

\section{Ethics}

All animal experimental procedures were approved by the Institute of Animal Care and Use Committee at Chang Gung Memorial Hospital, Kaohsiung Medical Center, Taiwan, China (Affidavit of Approval of Animal Use Protocol № 2008121108) and performed in accordance with the Guide for the Care and Use of Laboratory Animals (NIH publication No 85-23, National Academy Press, Washington, DC, USA, revised 1996).

\section{Animal grouping and induction of acute kidney ischemia-reperfu- sion injury}

Pathogen-free, adult male Sprague-Dawley (SD) rats $(n=32)$ weighing about $350 \mathrm{~g}$ (Charles River Technology, BioLASCO, Taiwan, China) were equally categorized into group 1 (sham controls, $n=8$ ), group 2 (acute kidney IR injury only, $n=8$ ), sitagliptin ( $300 \mathrm{mg} / \mathrm{kg}$ at post-IR 1,24 and $48 \mathrm{~h}$, orally, $n=8)$, and group 4 (IR+600 mg/ $\mathrm{kg}$ at post-IR 1, 24 and $48 \mathrm{~h}$, orally, $n=8)$. The rats were sacrificed at post-IR $72 \mathrm{~h}$ to determine the therapeutic effects of sitagliptin.

All animals were anesthetized by inhalation of $2.0 \%$ isoflurane, placed in a supine position on a warming pad at $37^{\circ} \mathrm{C}$ for midline laparotomies. Sham-operated rats (group 1) received laparotomy only, while acute IR injury of both kidneys was induced in all animals in groups 2 to 4 by clamping the renal pedicles for $1 \mathrm{~h}$ using non-traumatic vascular clips. The rats were sacrificed at $72 \mathrm{~h}$ after IR procedure, and kidneys were harvested for individual study.

\section{Safety and rationale for drug dosage}

To assess the safety of low- and high-dose sitagliptin in the experimental animals, we regularly monitored the blood glucose level for $5 \mathrm{~d}$ in 6 additional animals (ie, 3 for low-dose and 3 for high-dose sitagliptin). Serum blood glucose level of each animal was examined twice a day (ie, between 8:00-9:00 AM and $4 \mathrm{~h}$ after sitagliptin administration, respectively) using a blood glucose monitor (ACCU-CHEK-Active; Roche). The results showed that blood glucose level did not differ between the baseline (ie, prior to sitagliptin therapy) and at $\mathrm{d} 5$ after sitagliptin therapy (Baseline: 8:00-9:00 AM, 85 $\pm 4.6 \mathrm{mg} / \mathrm{dL} ; 4 \mathrm{~h}$ after sitagliptin administration, $88 \pm 4.8 \mathrm{mg} / \mathrm{dL}$. Low-dose sitagliptin at d 5: 8:00-9:00 AM, 84 $\pm 5.9 \mathrm{mg} / \mathrm{dL} ; 4 \mathrm{~h}$ after sitagliptin administration, $86 \pm 4.3 \mathrm{mg} / \mathrm{dL}$. High-dose sitagliptin at $\mathrm{d} 5$ : 8:00-9:00 AM, 88 $\pm 4.9 \mathrm{mg} / \mathrm{dL} ; 4 \mathrm{~h}$ after sitagliptin administration, $83 \pm 5.8 \mathrm{mg} / \mathrm{dL}, P>0.05)$.

To elucidate the relatively suitable drug dosages for the present study, four additional rats in acute kidney IR injury were treated with either a low- $(n=2)$ or a high- $(n=2)$ dose sitagliptin (ie, 300 or $600 \mathrm{mg} \cdot \mathrm{kg}^{-1} \cdot \mathrm{d}^{-1}$ three times after the IR procedure, respectively). Immunohistochemical (IHC) staining for the protein expression of glucagon-like peptide- 1 receptor (GLP-1R) in kidney parenchyma showed notably elevated expression of GLP-1R in the rats treated with high-dose sitagliptin compared with those receiving low dosage. Thus, 300 $\mathrm{mg} \cdot \mathrm{kg}^{-1} \cdot \mathrm{d}^{-1}$ and $600 \mathrm{mg} \cdot \mathrm{kg}^{-1} \cdot \mathrm{d}^{-1}$ were defined as low- and highdose sitagliptin, respectively, and administered to experimental animals for three consecutive days in the current study.

\section{Assessment of renal function before and after IR procedure}

Serum GLP-1, creatinine, blood urea nitrogen (BUN), urine protein, and urine creatinine levels were determined in all animals before and after (at $72 \mathrm{~h}$ ) the IR procedure prior to sacrifice. Quantification of GLP-1 level, BUN, serum and urine creatinine, and urine protein levels was performed using standard methods according to manufacturers' instructions.

\section{Collection of 24-h urine prior to and at $\mathbf{7 2} \mathrm{h}$ after IR procedure}

For the collection of 24-h urine for individual study, each animal was put into an animal metabolic cage (DXL-D, space: 190 $\mathrm{mm} \times 290 \mathrm{~mm} \times 550 \mathrm{~mm}$, Suzhou Fengshi Laboratory Animal Equipment Co Ltd, Suzhou, China) for $24 \mathrm{~h}$ with food and water supply. Urine was collected from all animals for $24 \mathrm{~h}$ prior to the IR procedure and at $72 \mathrm{~h}$ after reperfusion prior to sacrifice to determine the daily urine volume and the ratio of urine protein to urine creatinine.

Histopathology scoring and immunofluorescent staining at $72 \mathrm{~h}$ after IR

Histopathology scoring was determined in a blinded fashion 
as previously reported ${ }^{[22]}$. Briefly, the kidney specimens from all animals were fixed in $10 \%$ buffered formalin, embedded in paraffin, sectioned at $5 \mu \mathrm{m}$ and stained (hematoxylin and eosin, H\&E) for light microscopy. The scoring system reflecting the grading of tubular necrosis, loss of brush border, cast formation, and tubular dilatation in 10 randomly chosen, nonoverlapping fields $(200 \times)$ was as follows: 0 (none), $1(\leq 10 \%), 2$ $(11 \%-25 \%), 3(26 \%-45 \%), 4(46 \%-75 \%)$, and $5(\geq 76 \%)^{[27]}$.

The immunohistochemical (IHC) and immunofluorescent (IF) staining methods used in this study have been described in details elsewhere ${ }^{[22]}$. For IHC staining, rehydrated paraffin sections were first treated with $3 \% \mathrm{H}_{2} \mathrm{O}_{2}$ for 30 min and incubated with Immuno-Block reagent (BioSB) for $30 \mathrm{~min}$ at room temperature. Sections were then incubated with primary antibody specifically against $\mathrm{NAD}(\mathrm{P}) \mathrm{H}$ quinone oxidoreductase 1 (NQO 1) (Abcam) at $4{ }^{\circ} \mathrm{C}$ overnight. IF staining was performed using respective primary antibody against CD68 (Abcam), HO-1 (Abcam), CXCR4 (Santa Cruz), SDF-1a (Santa Cruz) at $4{ }^{\circ} \mathrm{C}$ overnight with irrelevant antibodies being used as controls. For quantification, three randomly selected HPFs ( $\times 200$ for IHC and IF studies) were analyzed in each section. The mean number per HPF for each animal was then determined by summation of all numbers divided by 9 .

\section{Western blot analysis of kidney specimens}

Equal amounts (10-30 $\mu \mathrm{g})$ of protein extracts from ischemic kidneys of the animals ( $n=8$ for each group) were loaded and separated by SDS-PAGE using $7 \%$ or $12 \%$ acrylamide gradients. The membranes were incubated with monoclonal antibodies against GLP-1R (1:1000, Abcam), matrix metalloproteinase-9 (MMP-9) (Millipore), NQO 1 (Abcam), heme oxygenase-1 (HO-1) (Abcam), polyclonal antibodies against tumor necrosis factor-alpha (TNF-a) (Cell Signaling), nuclear factorkappa B (NF-kB) (Abcam), NADPH oxidases NOX-1 (Sigma) and NOX-2 (Sigma), Bax (Abcam), caspase 3 (Cell Signaling), poly(ADP-ribose) polymerase (PARP) (Cell Signaling), and superoxide dismutase 1 (SOD-1) (Abcam) were used. Signals were detected with horseradish peroxidase (HRP)-conjugated goat anti-mouse, goat anti-rat, or goat anti-rabbit IgG.

The Oxyblot Oxidized Protein Detection Kit was purchased from Chemicon (S7150). The procedure of 2,4-dinitrophenylhydrazine (DNPH) derivatization was carried out on $6 \mu \mathrm{g}$ of protein for 15 min according to the manufacturer's instructions. One-dimensional electrophoresis was carried out on $12 \%$ SDS/polyacrylamide gel after DNPH derivatization. Proteins were transferred to nitrocellulose membranes which were then incubated in the primary antibody solution (antiDNP 1:150) for $2 \mathrm{~h}$, followed by incubation with the second antibody solution (1:300) for $1 \mathrm{~h}$ at room temperature. The washing procedure was repeated eight times within $40 \mathrm{~min}$.

Immunoreactive bands were visualized by enhanced chemiluminescence (ECL; Amersham Biosciences), which was then exposed to Biomax L film (Kodak). For quantification, ECL signals were digitized using Labwork software (UVP). For oxyblot protein analysis, a standard control was loaded on each gel.

\section{Statistical analysis}

Quantitative data are expressed as mean \pm SD. Statistical analyses were performed using SAS statistical software for Windows version 8.2 (SAS Institute, Cary, NC, USA) to conduct ANOVA followed by Bonferroni multiple-comparison post hoc test. $P$ values of less than 0.05 were considered statistically significant.

\section{Results}

Circulating level of GLP-1 and expression of GLP-1R in kidney at $72 \mathrm{~h}$ after IR procedure

At baseline, the circulating level of GLP-1 did not differ among the four groups. However, by $72 \mathrm{~h}$ after the IR procedure, the circulating level of GLP-1 was lowest in group 1 (sham control), highest in group $4\left(\mathrm{IR}+600 \mathrm{mg} \cdot \mathrm{kg}^{-1} \cdot \mathrm{d}^{-1}\right)$, and significantly higher in group 3 than in group 2 (Figure 1A, 1B). Additionally, when the 4 animals used in the pilot study were included, Western blot (Figure 1C) and IHC (Figure 1D) showed that expression of GLP-1R in kidney was markedly increased in group 4 in comparison with other groups, increased in group 3 in comparison with groups 1 and 2, and more increased in group 2 than in group 1.

Circulating level of BUN and creatinine, and the ratio of urine protein to creatinine prior to and at $72 \mathrm{~h}$ after acute IR injury

Prior to the IR induction, the serum levels of BUN (Figure 2A) and creatinine (Figure 2C) were similar among the four groups. However, at $72 \mathrm{~h}$ after IR procedure, the serum levels of BUN (Figure 2B) and creatinine (Figure 2D) were highest in group 2 and lowest in group 1, significantly higher in group 3 than in group 4.

The daily urine amount prior to the IR procedure did not differ among the four groups (Figure 2E). However, the daily urine amount was significantly less in group 2 than the other groups, significantly less in group 1 than in groups 3 and 4, and significantly less in group 3 as compared to that of the group 4 at $72 \mathrm{~h}$ after reperfusion (Figure $2 \mathrm{~F}$ ).

The ratio of urine protein to urine creatinine prior to the IR procedure was similar among the four groups (Figure $2 \mathrm{G}$ ). However, by $72 \mathrm{~h}$ after the IR procedure, the ratio of urine protein to urine creatinine was highest in group 2, lowest in group 1, and significantly higher in group 3 than in group 4 (Figure 2H).

\section{Histopathological scores and renal infiltration of CD68+ cells at $72 \mathrm{~h}$ after IR injury}

To determine the therapeutic effect of a lower versus a higher dosage of sitagliptin in protecting IR-induced acute kidney injury, histological scoring was adopted based on the typical microscopic features of acute tubular damage, including extensive tubular necrosis and dilatation, as well as cast formation and loss of brush border. The injury scoring was significantly higher in group 2 than in the other groups, significantly higher in groups 3 and 4 than in group 1, and significantly higher in group 3 than in group 4 at $72 \mathrm{~h}$ after IR procedure (Figure $3 \mathrm{~A}-3 \mathrm{E})$. 

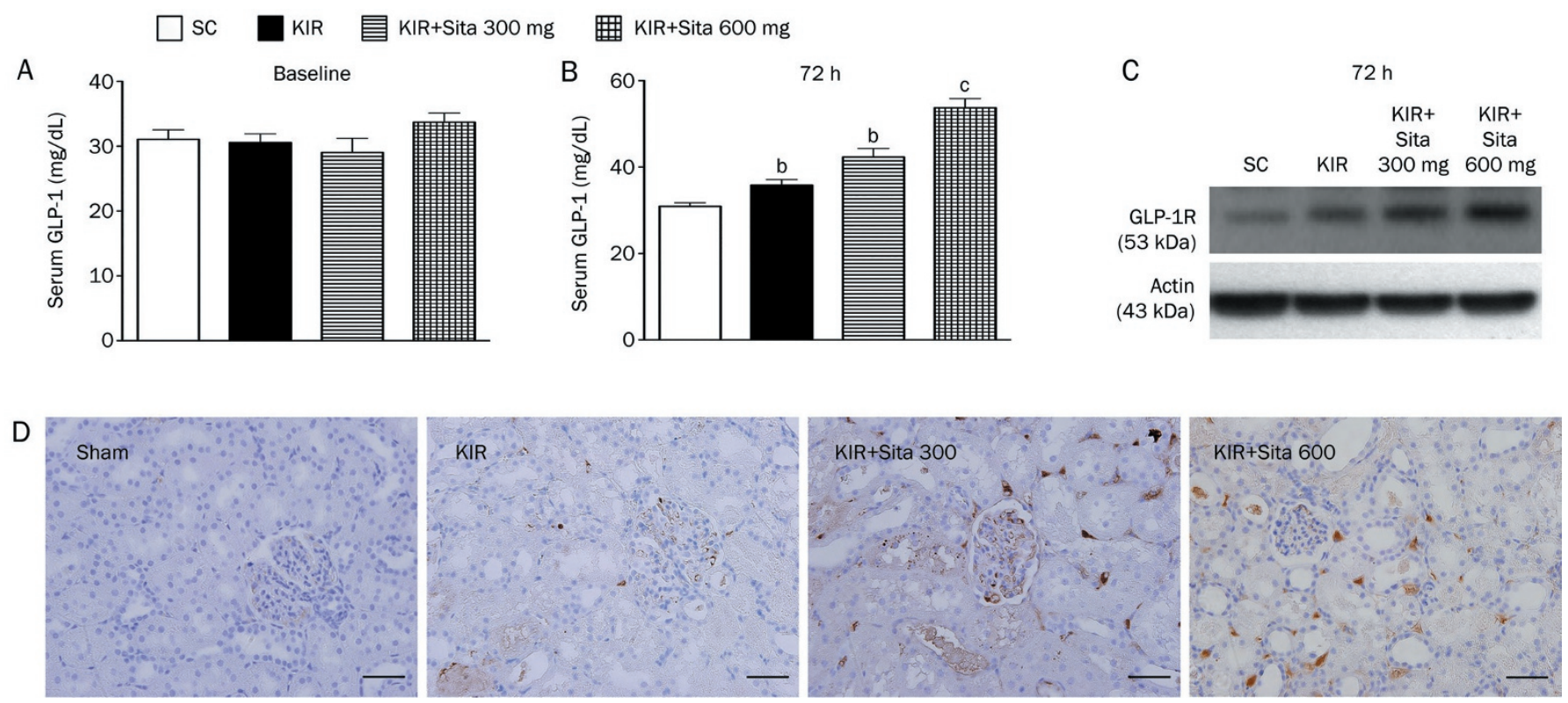

Figure 1. Circulating level of glucagon-like peptide-1 (GLP-1) and expression of GLP-1R in kidney at $72 \mathrm{~h}$ after IR procedure ( $n=8$ for each group). (A) Circulating GLP-1 level at baseline, $P>0.05$. (B) Circulating GLP-1 level at $72 \mathrm{~h}$ after acute kidney ischemia-reperfusion (IR) procedure: ${ }^{\circ} P<0.01$ vs sham control, ${ }^{b} P=0.05$ vs other groups. All statistical analyses using one-way ANOVA, followed by Bonferroni multiple comparison post hoc test. (C) Protein expression of GLP-1R in kidney at $72 \mathrm{~h}$ after acute IR procedure showing notably highest in kidney IR (KIR)+sitagliptin (Sita) $600 \mathrm{mg}$, lowest in sham control (SC), and notably higher in KIR+Sita $300 \mathrm{mg}$ than in KIR only ( $n=2$ in each group). (D) Microscopic (200x) findings of immunohistochemical (IHC) staining demonstrated that the GLP-1 receptor (GLP-1R) (brown color) in kidney at $72 \mathrm{~h}$ after acute IR procedure was notably highest in kidney IR (KIR)+sitagliptin (Sita) 600 mg, lowest in sham control (SC), and notably higher in KIR+Sita 300 mg than in KIR only. Scale bars in right lower corner represent $50 \mu \mathrm{m}$.

IF staining demonstrated that the number of CD68+ cells (ie, macrophages), an index of inflammation, was highest in group 2 and lowest in group 1, and significantly higher in group 3 than that in group 4 at $72 \mathrm{~h}$ after reperfusion (Figure $3 \mathrm{~F}-3 \mathrm{~J}$ ).

\section{Expression of glucagon-like peptide-1 receptor in kidney at $72 \mathrm{~h}$} after reperfusion

IHC showed that renal GLP-1R expression was highest in group 4 and lowest in group 1, and significantly higher in group 3 than in group 2 at $72 \mathrm{~h}$ after the IR procedure (Figure $4 \mathrm{~A}-4 \mathrm{E})$. Interestingly, the expression of this biomarker was found to be most frequent in the glomeruli, followed by in the renal tubular epithelium and least in the renal interstitial region. Additionally, the protein expression of GLP-1R in the renal parenchyma showed an identical pattern to the IHC findings (Figure 4F). These findings suggest that GLP$1 R$ expression was auto-regulated after acute kidney IR injury and there was an inverse correlation between the severity of renal IR injury and GLP-1R expression in renal parenchyma. Additionally, sitagliptin therapy augmented the expression of GLP-1R in renal parenchyma, and the expression was particularly prominent in the glomeruli (Figure 4A-4D).

Protein expressions of inflammatory and apoptotic biomarkers at $72 \mathrm{~h}$ after IR injury

The protein expressions of TNF- $\alpha$ (Figure 5A), NF-KB (Figure
5B), and MMP-9 (Figure 5C), three indicators of inflammation, were significantly higher in group 2 than in the other groups, significantly higher in groups 3 and 4 than that in group 1, and significantly higher in group 3 than in group 4 at $72 \mathrm{~h}$ after the IR procedure. These findings suggest that a higher dosage of sitagliptin has higher anti-inflammatory capacity. In addition, the protein expression of mitochondrial Bax (Figure 5D), cleaved (ie, active form) caspase 3 (Figure 5E) and cleaved PARP (Figure 5F), three indices of apoptosis, exhibited a pattern similar to that of inflammatory biomarkers.

Protein expression of oxidative-stress, reactive oxygen species (ROS) and anti-oxidant biomarkers at $72 \mathrm{~h}$ after IR injury

The protein expression of NOX-1 (Figure 6A) and NOX-2 (Figure 6B), two indices of ROS, were highest in group 2 and lowest in group 1, and significantly higher in group 3 than group 4. Additionally, the expression of oxidized protein, an index of oxidative stress, displayed a pattern similar to that of ROS among the four groups (Figure 6C).

The protein expression of SOD-1 (Figure 6D), a scavenger of superoxide, was lowest in group 1 and highest in group 4 , and significantly lower in group 2 than that in group 3 at $72 \mathrm{~h}$ after IR procedure. Additionally, the protein expressions of HO-1 (Figure 6E) and NQO-1 (Figure 6F), two indicators of antioxidative activities, exhibited an identical pattern to SOD-1 expression among the four groups at $72 \mathrm{~h}$ after IR induction. 
A

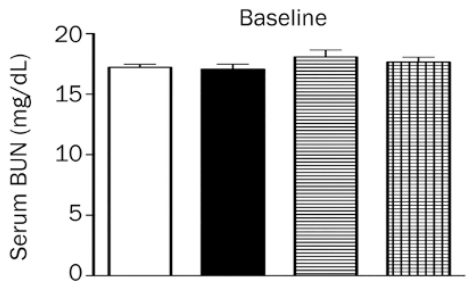

C

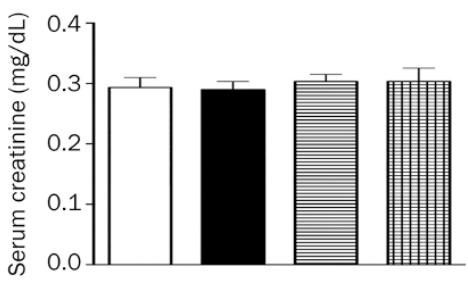

E

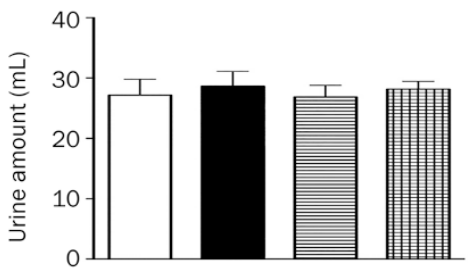

G

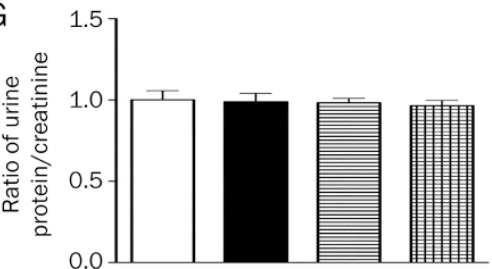

B

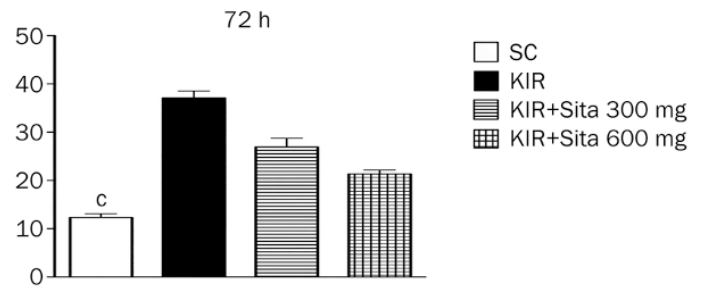

D

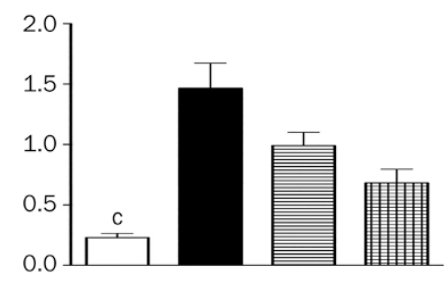

F

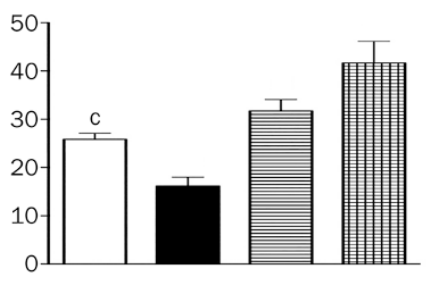

$\mathrm{H}$

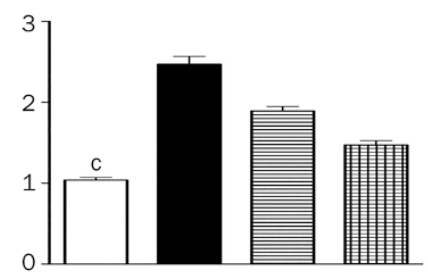

Figure 2. BUN and creatinine levels, and the ratio of urine protein to creatinine prior to and at $72 \mathrm{~h}$ after acute kidney IR injury ( $n=8$ for each group). (A) Serum blood urea nitrogen (BUN) level prior to IR procedure (ie, at baseline), $P>0.05$. (B) Serum BUN level at $72 \mathrm{~h}$ after IR procedure, ${ }^{\mathrm{C}} P<0.01 \mathrm{vs}$ other groups with different symbols. (C) Serum creatinine level prior to IR procedure, $P>0.05$. (D) Serum creatinine level at $72 \mathrm{~h}$ after IR procedure, ${ }^{\mathrm{C}} P<0.01$ vs other groups with different symbols. (E) Urine amount prior to IR procedure, $P>0.05$. (F) Urine amount at $72 \mathrm{~h}$ after the procedure, ${ }^{\mathrm{C}} P<0.01 \mathrm{vs}$ other groups with different symbols. $(G)$ The ratio of urine protein to creatinine prior to IR procedure, $P>0.05$. $(H)$ The ratio of urine protein to creatinine at $72 \mathrm{~h}$ after IR procedure, ${ }^{\mathrm{C}} \mathrm{P}<0.01$ vs other groups with different symbols. All statistical analyses using one-way ANOVA, followed by Bonferroni multiple comparison post hoc test. SC, sham control; KIR, kidney ischemia reperfusion; Sita, sitagliptin.

IHC and IF microscopic findings of anti-oxidant cellular expressions

The cellular expression of HO-1 (Figure 7A-7E) as assessed by IF staining and NQO 1 (Figure 7F-7J) as assessed by IHC, was lowest in group 1 and highest in group 4, and significantly lower in group 2 than that in group 3 at $72 \mathrm{~h}$ after IR procedure.

Cellular expression of angiogenesis at $72 \mathrm{~h}$ after IR injury

The IF microscopic findings of kidney parenchyma showed that CXCR4+ (Figure 8A-8E) and SDF-1a+ cells (Figure 8F-8J), two markers of angiogenesis cells were lowest in group 1, highest in group 4, and significantly higher in group 3 than in group 2.

\section{Discussion}

This study investigated the impact of sitagliptin therapy on reducing acute IR kidney injury. Several observations were made. First, acute IR kidney injury elicited a rigorous inflammatory reaction, oxidative stress and generation of ROS. Second, a higher dosage of sitagliptin $\left(600 \mathrm{mg} \cdot \mathrm{kg}^{-1} \cdot \mathrm{d}^{-1}\right)$ was more effective than a low dosage of sitagliptin $\left(300 \mathrm{mg} \cdot \mathrm{kg}^{-1} \cdot \mathrm{d}^{-1}\right)$ in reducing kidney damage scoring, proteinuria and preserving renal function. Third, a higher dosage of sitagliptin was more effective than a low dosage of sitagliptin at ameliorating inflammation, apoptosis, and generation of oxidative stress and ROS. Fourth, importantly, no harmful/toxic effects were found with either dosage of sitagliptin in the setting of acute IR kidney with impaired renal function.

The most important finding in the present study was that kidney injury scoring was markedly increased in acute IR animals and this increase was significantly reversed by a lower dosage of sitagliptin therapy and further significantly reversed by higher dosage of sitagliptin treatment. Addition- 

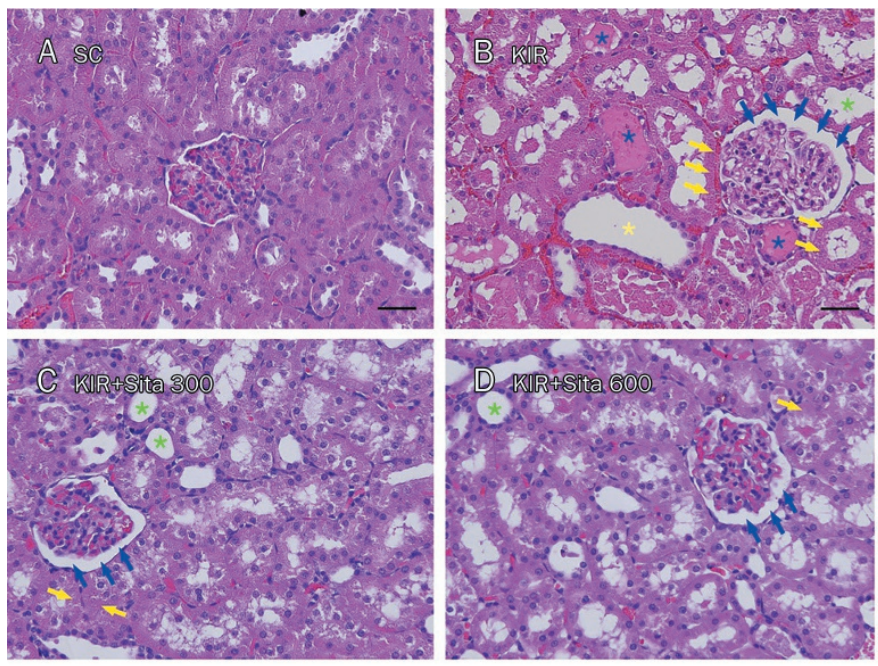

\section{E}

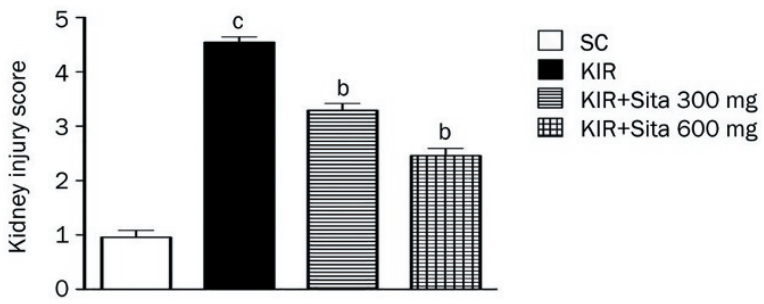

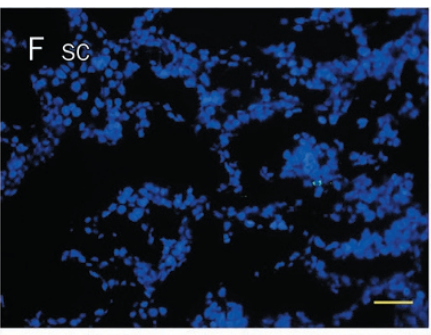
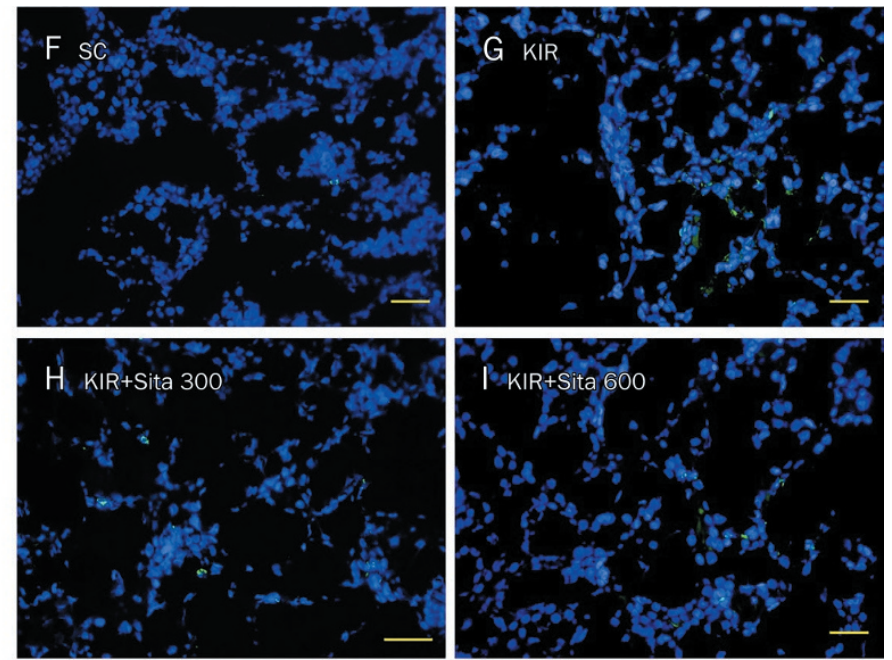

J

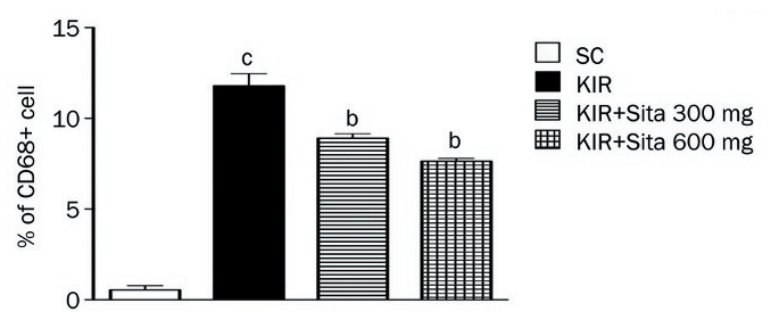

Figure 3. Histopathological scores and inflammatory cell infiltration in kidney at $72 \mathrm{~h}$ after IR injury ( $n=8$ for each group). (A-D) H\&E stain (200x) showing significantly higher degree of loss of brush border in renal tubules (green asterisk), cast formation (blue asterisk), tubular dilatation (yellow asterisk), tubular necrosis (yellow arrows), and dilatation of Bowman's capsule (blue arrows) in KIR only group than in other groups at $72 \mathrm{~h}$ (A-D) after IR procedure. (E) The analytical results of kidney injury score at $72 \mathrm{~h}$ after IR procedure: ${ }^{\circ} P<0.01$ vs sham control, ${ }^{b} P=0.05$ vs other groups. ( $F-I$ IF microscopic findings (200x) showing the percentage of CD68+ cell infiltration (green signals) in kidney parenchyma among four groups at $72 \mathrm{~h}$ ( $\mathrm{F}-\mathrm{I}$ ) after IR procedure. (J) The analytical results of CD68+ cells in kidney parenchyma at $72 \mathrm{~h}$ after IR procedure: ${ }^{\mathrm{C}} P<0.01 \mathrm{vs}$ sham control, ${ }^{\mathrm{b}} \mathrm{P}=0.05 \mathrm{vs}$ other groups. All statistical analyses using one-way ANOVA, followed by Bonferroni multiple comparison post hoc test. Scale bars in right lower corner represent $50 \mu \mathrm{m}$. SC, sham control; KIR, kidney ischemia reperfusion; Sita, sitagliptin.

ally, circulating levels of BUN and creatinine were substantially elevated in acute IR animals and were reduced by lower dosage of sitagliptin treatment and more further reduced by higher dosage of sitagliptin treatment. Furthermore, the ratio of urine protein to creatinine was markedly increased in acute IR animals and was markedly reduced after administration of a lower dosage of sitagliptin and further reduced by a higher dosage of sitagliptin. These findings suggest that sitagliptin therapy can protect the kidney from acute IR injury. Additionally, these findings suggest the possible usefulness of clinical application of sitagliptin in the setting of acute kidney injury, especially in those patients with a medical history of diabetes mellitus.

Compared to sham controls, the level of inflammatory mediators in kidney parenchyma was markedly augmented in acute IR animals. Previous studies have shown that acute IR always initiates a cascade of inflammatory processes ${ }^{[22,23]}$. Additionally, our recent study also found that acute IR kidney injury elicited a tremendous inflammatory reaction ${ }^{[28]}$. The result of present study is consistent with the previous findings ${ }^{[22,23,28]}$. Expression of these inflammatory mediators were notably suppressed by a low dosage of sitagliptin and further significantly suppressed by higher dosage of this drug. The generation of oxidative stress and ROS was markedly enhanced in acute kidney IR animals in comparison to the sham controls. The results of previous studies ${ }^{[22,23,28]}$ also revealed similar findings in similar setting of acute IR organ injury. The generations of the oxidative stress and ROS were ameliorated by a low dosage of sitagliptin treatment and further ameliorated by a higher dosage of sitagliptin. Hence, our findings not only strengthen the findings of the studies ${ }^{[22,23,28]}$ but also demonstrate that sitagliptin has the capacity to suppress the inflammatory reaction and generation of oxidative stress and ROS. Our findings therefore, at least in part, explain why sitagliptin therapy attenuates the kidney injury and preserve the renal function after acute IR injury at the cellular and molecular level.

Mitochondrial damage ${ }^{[20-22]}$ and cellular apoptosis ${ }^{[19,21,28]}$ have also been reported to be frequent findings after IR injuries in solid organs. In the present study, we found that compared with the sham control, the protein expression of apoptotic biomarkers (ie, mitochondrial Bax, cleaved caspase 3 and PARP) were markedly enhanced in the acute IR kidney. Our findings, therefore, corroborated the findings from previ- 

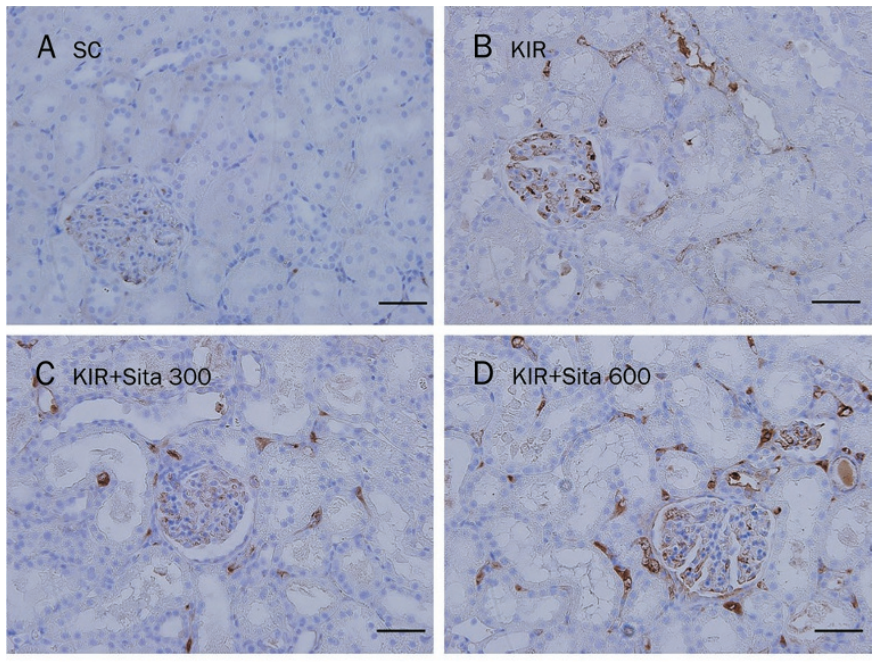

$\mathrm{E}$
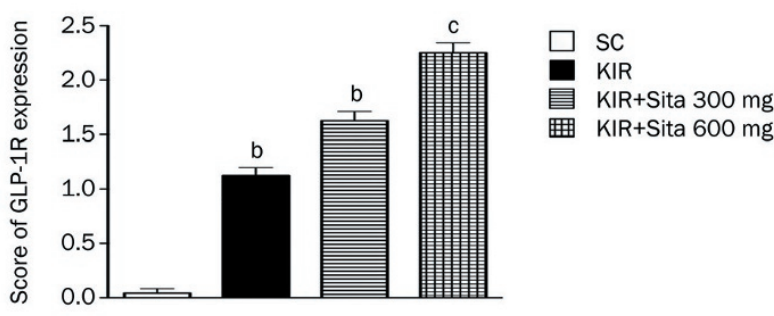

$\mathrm{F}$
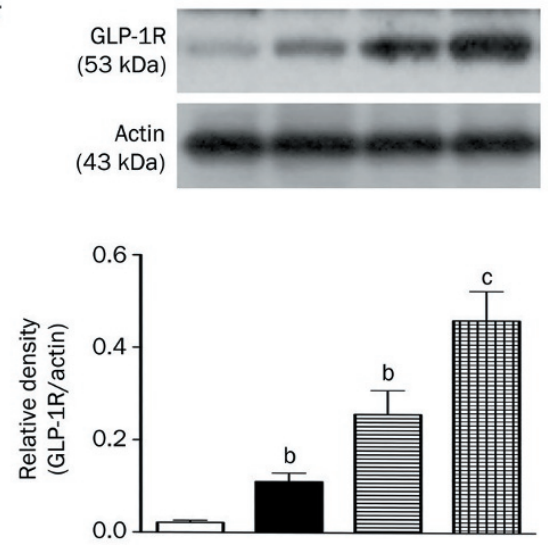

Figure 4. IHC findings and protein expression of glycogen-like peptide-1 receptor (GLP-1R) in kidney at $72 \mathrm{~h}$ after IR injury ( $n=8$ for each group). (A-D) The IHC stain (200x) identifying the GLP-1R (brown color) in kidney parenchyma among four groups at $72 \mathrm{~h}(\mathrm{~A}-\mathrm{D})$ after IR procedure. (E) ${ }^{c} P<0.01$ vs sham control, ${ }^{b} P=0.05$ vs other groups. Scale bars in right lower corner represent $50 \mu \mathrm{m}$. (F) The protein expression of GLP-1R in kidney parenchyma among four group at $72 \mathrm{~h}$ after acute IR injury, ${ }^{\mathrm{c}} P<0.01$ vs sham control, ${ }^{\mathrm{b}} P=0.05$ vs other groups. All statistical analyses using one-way ANOVA, followed by Bonferroni multiple comparison post hoc test. SC, sham control; KIR, kidney ischemia reperfusion; Sita, sitagliptin.

ous studies ${ }^{[19-23,28]}$. The protein expression of these apoptotic parameters was down-regulated after administration of a low dose of sitagliptin and they were further down-regulated after higher dose of sitagliptin treatment. Additionally, the protein expression of antioxidant biomarkers (SOD, HO-1, NQO 1, GR, GPx) were blunted in acute IR animals and upregulated in animals receiving a low dosage of sitagliptin and further up-regulated in animals receiving a higher dosage of sitagliptin. These findings, highlight that sitagliptin inhibits cellular apoptosis and augments anti-oxidant effects.

Interestingly, having the close interrelationship between inflammation, oxidative stress, cellular apoptosis and organ damage in various settings of ischemia, ischemia/reperfusion injury have been well established ${ }^{[20-22,27,28]}$. Actually, these parameters have always been found to be closely and mutually affect each other ${ }^{[27,28]}$. In the present study, we not only found that all of these biomarkers were upregulated together but also found that the perturbations of these parameters were remarkably reduced along with enhancement of GLP$1 \mathrm{R}$ expression and anti-oxidants in kidney parenchyma after the sitagliptin treatment under IR injury. These findings indirectly reflect an intimate axis of GLP-1R/GLP-1 for the augmentation of anti-inflammation, anti-oxidative stress and anti ROS after sitagliptin therapy.

Recently, we have shown that sitagliptin therapy enhances numbers of circulating endothelial progenitor cells (EPC), angiogenesis, and blood flow in the rat critical limb ischemia area $^{[27]}$. Interestingly, another experimental study has revealed that sitagliptin therapy enhanced neovascularization through increasing circulating number of EPCS ${ }^{[29]}$. Additionally, a clinical observational study has also shown that sitagliptin therapy increases the circulating level of EPCs in patients with type II diabetes mellitus ${ }^{[29,30]}$. Furthermore, other recent studies have also shown that sitagliptin therapy prevented the propagation of carotid intima-media thickening ${ }^{[31]}$ and protected against ischemia-related left ventricular dysfunction ${ }^{[32]}$. In this study, in acute kidney IR animals, the expression of EPCs (ie, CXCR4+, SDF-1a+) was higher with sitagliptin treatment than without. Additionally, as compared to a lower dosage of sitagliptin, the higher dosage of sitagliptin was more effective in up-regulating the EPC expression in the renal parenchyma. In this way, our study is consistent with the results of recent studies $^{[27,29-32]}$. Our finding of enhanced EPC expression in acute IR kidney injury supports the essential role of EPCs in repairing injured endothelial cells and participation in angiogenesis in response to ischemic insult from acute IR injury.

One intriguing finding in the present study is the significantly higher circulating GLP-1 level in IR animals without sitagliptin treatment than that in the sham controls, together with the highest level in IR animals receiving sitagliptin treatment. This finding may be due to stress stimulation from IR injury that enhanced the generation of GLP-1 from the digestive system.

This study has several limitations. First, although myriads of works had been in the current study, results of the study did not provide the exact mechanisms by which sitagliptin inhibits inflammation, oxidative stress and ROS, to protect kidney function after acute IR injury. The schematic in Figure 9 shows our proposed mechanisms of the therapeutic effect of 
A
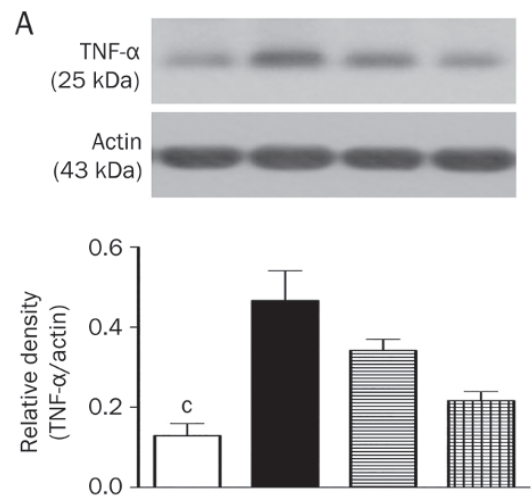

D
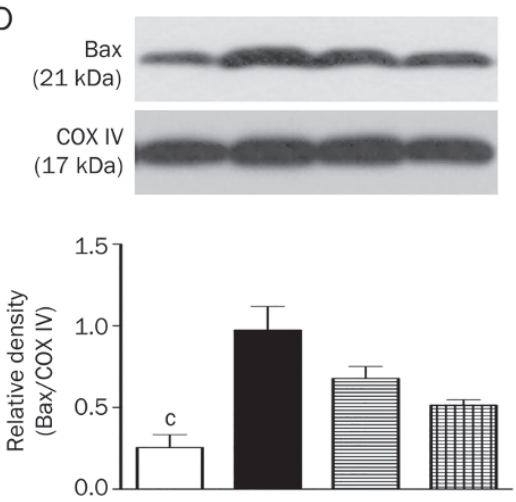

B
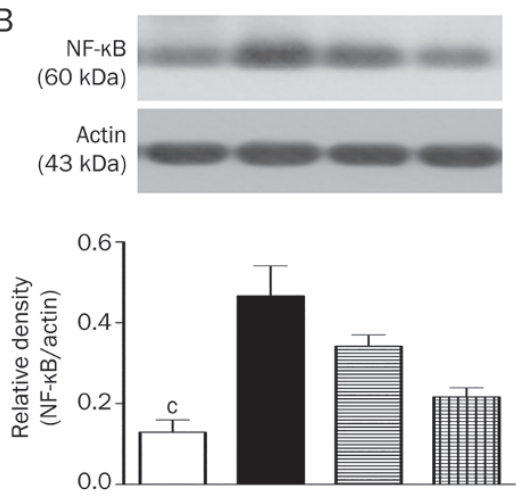

E
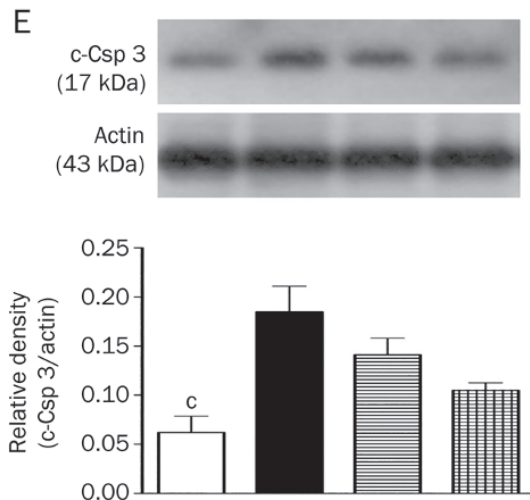

C
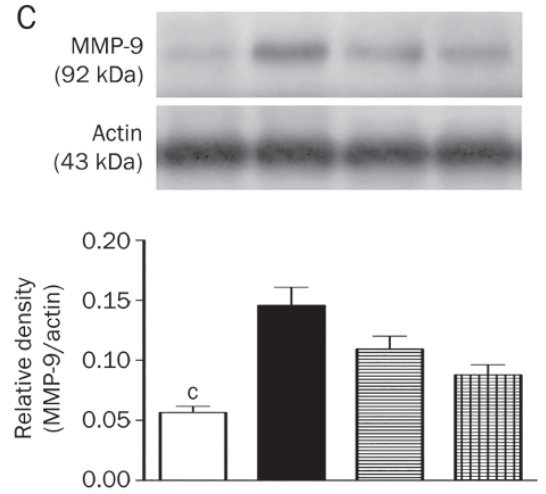

$\mathrm{F}$
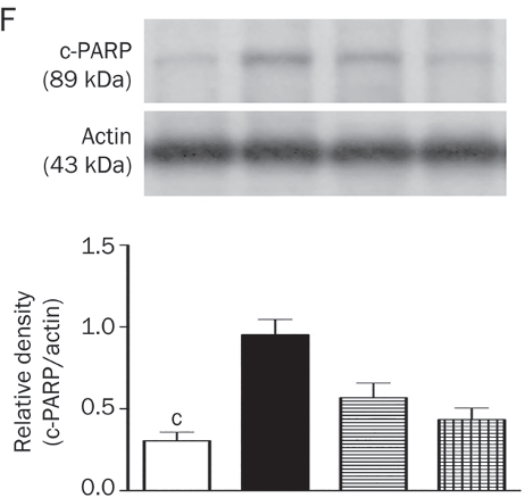

Figure 5. Protein expressions of inflammatory and apoptotic biomarkers at $72 \mathrm{~h}$ after IR injury ( $n=8$ for each group). (A) Analytical results of tumor necrosis factor TNF- $\alpha$ protein expression in kidney parenchyma at $72 \mathrm{~h}$ after IR procedure, ${ }^{c} P<0.01$ vs other groups. (B) Analytical results of nuclear factor NF-KB protein expression in kidney parenchyma at $72 \mathrm{~h}$ after IR procedure, ${ }^{\mathrm{C}} P<0.01$ vs other groups. (C) Analytical results of matrix metalloproteinase (MMP)-9 protein expression in kidney parenchyma at $72 \mathrm{~h}$ after IR procedure, ${ }^{\mathrm{C}} P<0.01$ vs other groups. (D) Analytical results of mitochondrial Bax protein expression in kidney parenchyma at $72 \mathrm{~h}$ after IR procedure, ${ }^{\mathrm{C}} \mathrm{P}<0.01$ vs other groups. (E) Analytical results of cleaved caspase 3 (c-CSP 3) protein expression in kidney parenchyma at $72 \mathrm{~h}$ after KIR procedure, ${ }^{\circ} P<0.01$ vs other groups. (F) Analytical results of cleaved PARP (C-PARP) protein expression in kidney parenchyma at $72 \mathrm{~h}$ after KIR procedure, ${ }^{c} P<0.01$ vs other groups. All statistical analyses using one-way ANOVA, followed by Bonferroni multiple comparison post hoc test. SC, sham control; KIR, kidney ischemia reperfusion; Sita, sitagliptin.

sitagliptin on protecting kidney injury based on our findings.

Second, without stepwise-increases in the concentrations of sitagliptin in the acute IR kidney injury animal model, this study could not ascertain the optimal therapeutic dosage of sitagliptin for acute renal IR.

Here, we concluded a higher dosage of sitagliptin is superior to a low dosage of sitagliptin for inhibition of inflammatory reaction and generation of oxidative stress and ROS, and therefore preservation of kidney function in the acute IR kidney injury setting.

\section{Acknowledgements}

This study was supported from Chang Gung Memorial Hospital, Chang Gung University, Taiwan, China (№ CMRPG 8B0331).

\section{Author contribution}

Meng-wei CHANG, Chih-hung CHEN, and Yi-ching CHEN participated in the design of the study, data acquisition and analysis as well as drafting the manuscript; Ying-Chun WU, Yen-yi ZHEN, Steve LEU, Tzu-hsien TSAI, and Sheung-fat KO were responsible for the laboratory assay and troubleshooting; Pei-hsun SUNG, Chih-chau YANG, Hsin-ju CHIANG, and Hsueh-wen CHANG participated in data acquisition, analysis, and interpretation; Yen-ta CHEN and Hon-kan YIP conceived of the study, and participated in its design and coordination and helped to draft the manuscript. All authors read and approved the final manuscript.

\section{References}

1 Jassal SV, Trpeski L, Zhu N, Fenton S, Hemmelgarn B. Changes in survival among elderly patients initiating dialysis from 1990 to 1999. CMAJ 2007; 177: 1033-8.

2 Coresh J, Selvin E, Stevens LA, Manzi J, Kusek JW, Eggers P, et al. Prevalence of chronic kidney disease in the United States. JAMA 2007; 298: 2038-47.

3 Stel VS, Kramer A, Zoccali C, Jager KJ. The 2006 ERA-EDTA Registry 

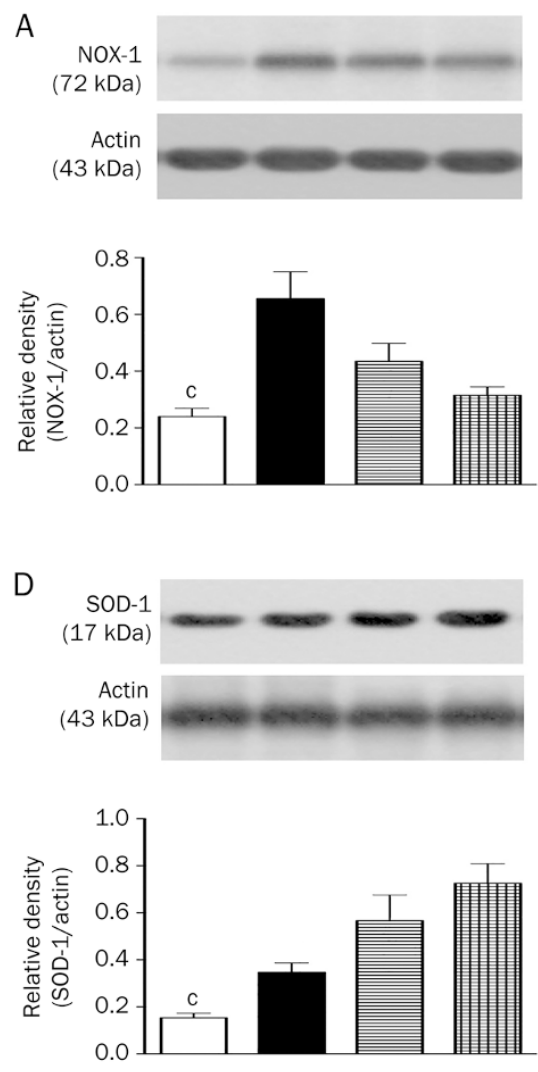
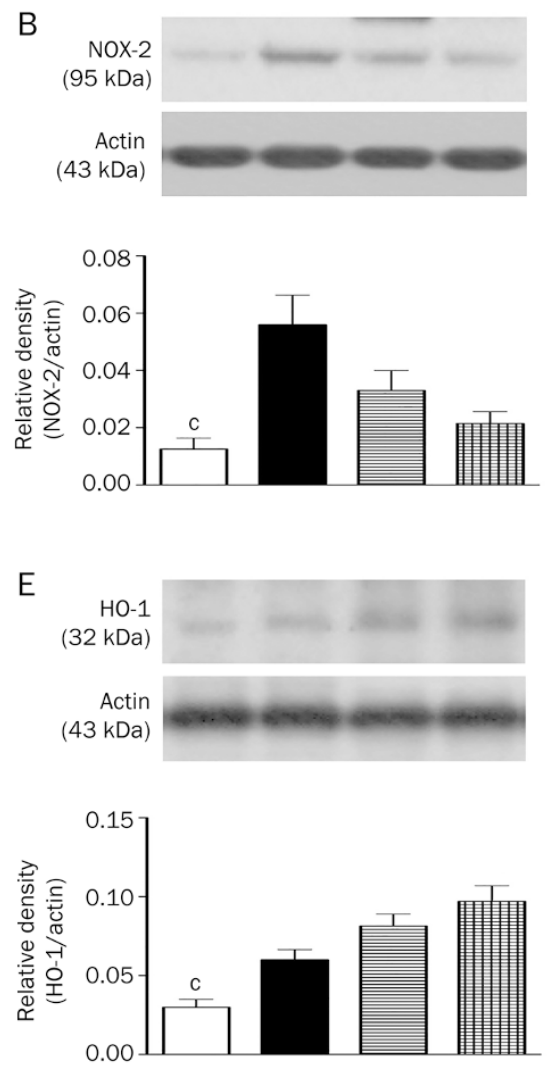

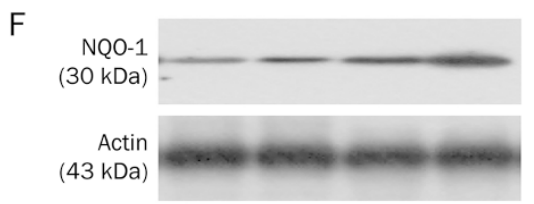

C
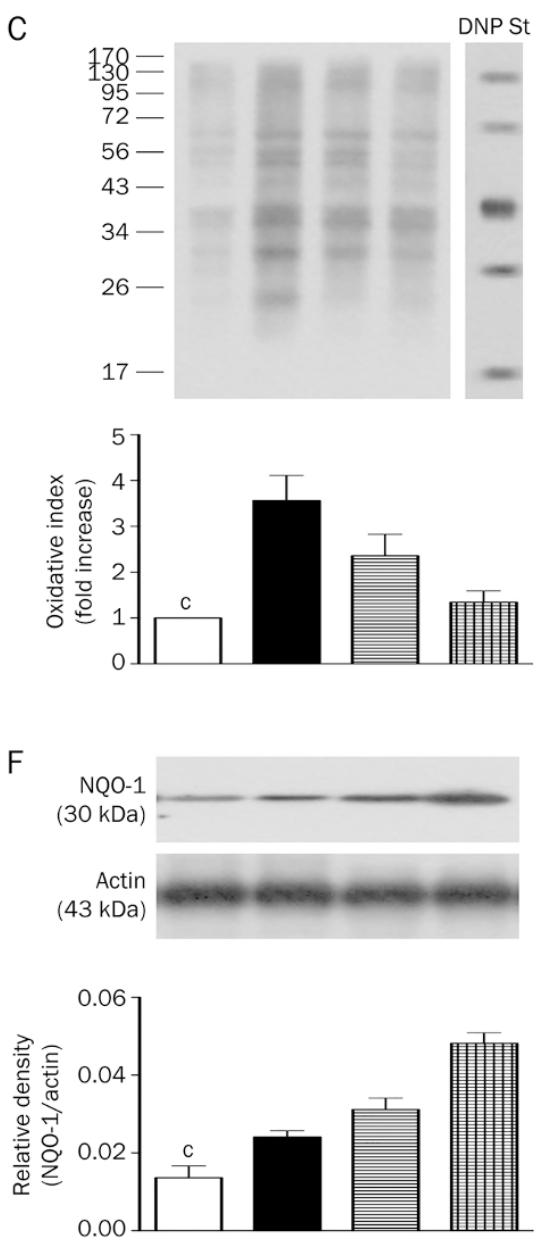

Figure 6. Protein expression of oxidative-stress, reactive oxygen species (ROS) and anti-oxidant biomarkers at $72 \mathrm{~h}$ after IR injury ( $n=8$ for each group). (A) Protein expression of NOX-1 in kidney parenchyma at $72 \mathrm{~h}$ after IR procedure, ${ }^{\mathrm{C}} \mathrm{P}<0.01$ vs other groups. (B) Protein expression of NOX-2 in kidney parenchyma at $72 \mathrm{~h}$ after IR procedure, ${ }^{\circ} P<0.01$ vs other groups. (C) Oxidative stress (ie, oxidized protein) in kidney parenchyma at $72 \mathrm{~h}$ after IR procedure, ${ }^{c} P<0.01$ vs other groups. (D) The protein expression of superoxide dismutase 1 (SOD-1), ${ }^{c} P<0.01$ vs other groups. (E) The protein expression of heme oxygenase-1 (HO-1), ${ }^{c} P<0.01$ vs other groups. (F) The protein expression of $\mathrm{NAD}(\mathrm{P}) \mathrm{H}$ quinone oxidoreductase-1 (NQO-1), ${ }^{\mathrm{c}} P<0.01$ vs other groups. All statistical analyses using one-way ANOVA, followed by Bonferroni multiple comparison post hoc test. SC, sham control; KIR, kidney ischemia reperfusion; Sita, sitagliptin.

annual report: a precis. J Nephrol 2009; 22: 1-12.

4 Arogundade FA, Barsoum RS. CKD prevention in Sub-Saharan Africa: a call for governmental, nongovernmental, and community support. Am J Kidney Dis 2008; 51: 515-23.

5 Grassmann A, Gioberge S, Moeller S, Brown G. ESRD patients in 2004: global overview of patient numbers, treatment modalities and associated trends. Nephrol Dial Transplant 2005; 20: 2587-93.

6 Dalrymple LS, Johansen KL, Chertow GM, Cheng SC, Grimes B, Gold $\mathrm{EB}$, et al. Infection-related hospitalizations in older patients with ESRD. Am J Kidney Dis 2010; 56: 522-30.

7 Collins AJ, Kasiske B, Herzog C, Chavers B, Foley R, Gilbertson D, et al. Excerpts from the United States Renal Data System 2004 annual data report: atlas of end-stage renal disease in the United States. Am J Kidney Dis 2005; 45: A5-7, S1-280.

8 Smyth A. End-stage renal disease and renal replacement therapy in older patients. Nephrourol Mon 2012; 4: 425-30.

9 Fang $\mathrm{Y}$, Ding $\mathrm{X}$, Zhong $\mathrm{Y}$, Zou J, Teng J, Tang Y, et al. Acute kidney injury in a Chinese hospitalized population. Blood Purif 2010; 30:
$120-6$

10 Lafrance JP, Miller DR. Acute kidney injury associates with increased long-term mortality. JASN 2010; 21: 345-52.

11 Chertow GM, Burdick E, Honour M, Bonventre JV, Bates DW. Acute kidney injury, mortality, length of stay, and costs in hospitalized patients. JASN 2005; 16: 3365-70.

12 Lameire N, Van Biesen W, Vanholder R. Acute renal failure. Lancet 2005; 365: 417-30.

13 Boros P, Bromberg JS. New cellular and molecular immune pathways in ischemia/reperfusion injury. Am J Transplant 2006; 6: 652-8.

14 Santos WJ, Zanetta DM, Pires AC, Lobo SM, Lima EQ, Burdmann EA. Patients with ischaemic, mixed and nephrotoxic acute tubular necrosis in the intensive care unit - a homogeneous population? Crit Care 2006; 10: R68.

15 Levy EM, Viscoli CM, Horwitz RI. The effect of acute renal failure on mortality. JAMA 1996; 275: 1489-94.

16 Xue JL, Daniels F, Star RA, Kimmel PL, Eggers PW, Molitoris BA, et al. Incidence and mortality of acute renal failure in Medicare 

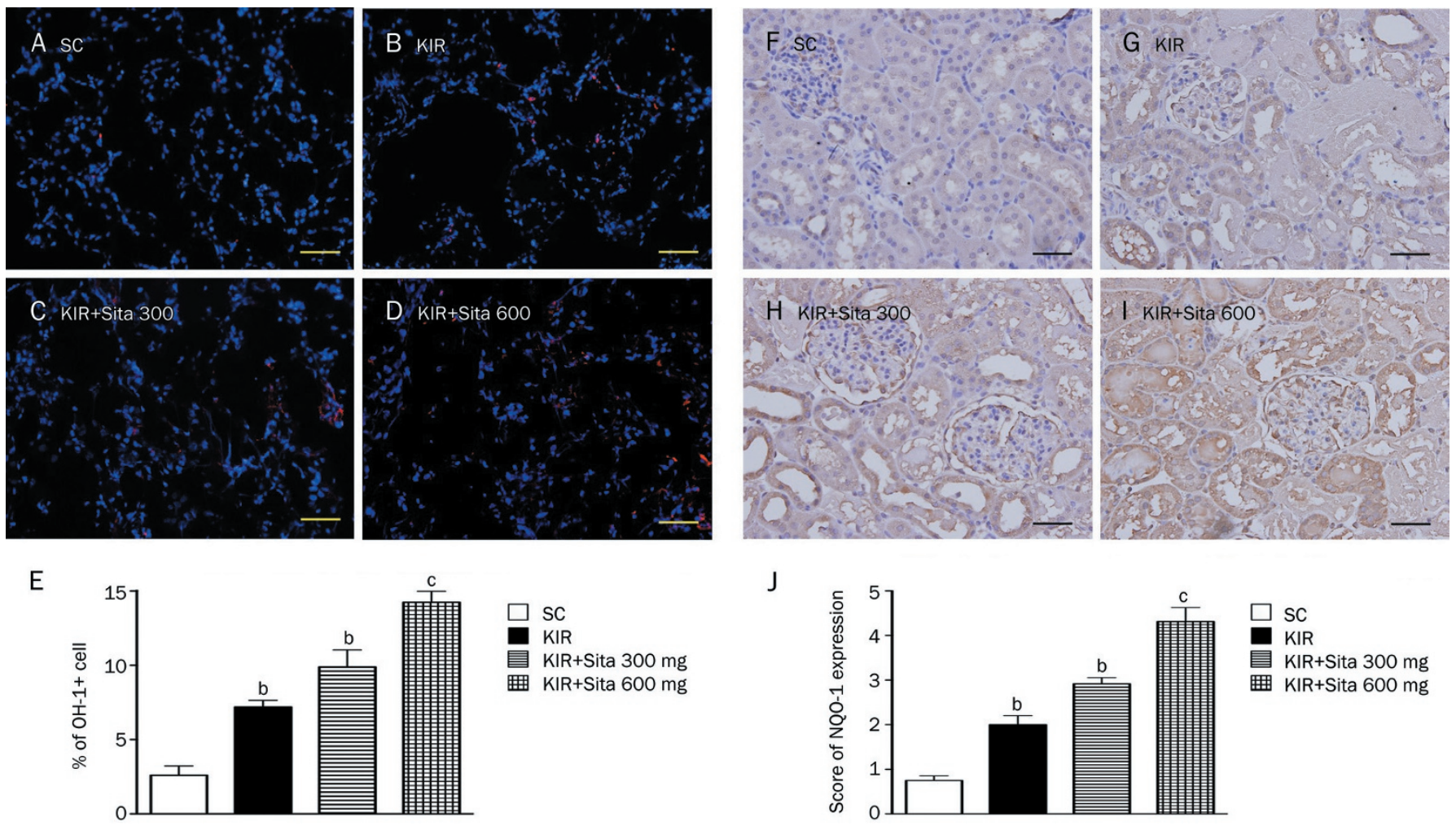

Figure 7. IF and IHC staining of anti-oxidant cellular expressions at $72 \mathrm{~h}$ after IR injury ( $\mathrm{n}=8$ for each group). (A-D) IF microscopic findings (200x) showing the number of HO-1+ cells in kidney parenchyma among four groups at $72 \mathrm{~h}$ after IR procedure. (E) The analytical results of $\mathrm{HO}-1+$ cells in kidney parenchyma at $72 \mathrm{~h}$ after IR procedure: ${ }^{\mathrm{C}} P<0.01$ vs sham control, ${ }^{\mathrm{b}} P=0.05$ vs other groups. (F-I) IHC staining of microscopic findings (200x) identifying the expression of NQO-1 cells in kidney parenchyma among four groups at $72 \mathrm{~h}$ after IR procedure. (J) The analytical results of NQO-1 cell expressions in kidney parenchyma at $72 \mathrm{~h}$ after IR procedure: ${ }^{\mathrm{C}} \mathrm{P}<0.01$ vs sham control, ${ }^{\mathrm{b}} \mathrm{P}=0.05$ vs other groups. Scale bars in right lower corner represent $50 \mu \mathrm{m}$. All statistical analyses were with one-way ANOVA followed by Bonferroni multiple comparison post hoc test. SC, sham control; KIR, kidney ischemia reperfusion; Sita, sitagliptin.

beneficiaries, 1992 to 2001. JASN 2006; 17: 1135-42.

17 Ali T, Khan I, Simpson W, Prescott G, Townend J, Smith W, et al. Incidence and outcomes in acute kidney injury: a comprehensive population-based study. JASN 2007; 18: 1292-8.

18 Parikh CR, Coca SG, Wang Y, Masoudi FA, Krumholz HM. Long-term prognosis of acute kidney injury after acute myocardial infarction. Arch Intern Med 2008; 168: 987-95.

19 Li B, Cohen A, Hudson TE, Motlagh D, Amrani DL, Duffield JS. Mobilized human hematopoietic stem/progenitor cells promote kidney repair after ischemia/reperfusion injury. Circulation 2010; 121: 2211-20.

20 Sun CK, Zhang XY, Zimmermann A, Davis G, Wheatley AM. Effect of ischemia-reperfusion injury on the microcirculation of the steatotic liver of the Zucker rat. Transplantation 2001; 72: 1625-31.

21 Sun CK, Zhang XY, Sheard PW, Mabuchi A, Wheatley AM. Change in mitochondrial membrane potential is the key mechanism in early warm hepatic ischemia-reperfusion injury. Microvasc Res 2005; 70 : 102-10.

22 Chen YT, Sun CK, Lin YC, Chang LT, Chen YL, Tsai TH, et al. Adiposederived mesenchymal stem cell protects kidneys against ischemiareperfusion injury through suppressing oxidative stress and inflammatory reaction. J TransI Med 2011; 9: 51.

23 da Silva LB, Palma PV, Cury PM, Bueno V. Evaluation of stem cell administration in a model of kidney ischemia-reperfusion injury. Int Immunopharmacol 2007; 7: 1609-16.
24 Scheen AJ. Dipeptidylpeptidase-4 inhibitors (gliptins): focus on drugdrug interactions. Clin Pharmacokinet 2010; 49: 573-88.

25 Zerilli T, Pyon EY. Sitagliptin phosphate: a DPP-4 inhibitor for the treatment of type 2 diabetes mellitus. Clin Ther 2007; 29: 2614-34.

26 Matsubara J, Sugiyama S, Sugamura K, Nakamura T, Fujiwara Y, Akiyama E, et al. A dipeptidyl peptidase-4 inhibitor, des-fluorositagliptin, improves endothelial function and reduces atherosclerotic lesion formation in apolipoprotein E-deficient mice. J Am Coll Cardiol 2012; 59: 265-76.

27 Chua S, Sheu JJ, Chen YL, Chang LT, Sun CK, Leu S, et al. Sitagliptin therapy enhances the number of circulating angiogenic cells and angiogenesis-evaluations in vitro and in the rat critical limb ischemia model. Cytotherapy 2013; 15: 1148-63.

28 Chen YT, Yang CC, Zhen YY, Wallace CG, Yang JL, Sun CK, et al. Cyclosporine-assisted adipose-derived mesenchymal stem cell therapy to mitigate acute kidney ischemia-reperfusion injury. Stem Cell Res Ther 2013; 4: 62.

29 Huang CY, Shih CM, Tsao NW, Lin YW, Huang PH, Wu SC, et al. Dipeptidyl peptidase-4 inhibitor improves neovascularization by increasing circulating endothelial progenitor cells. Br J Pharmacol 2012; 167: 1506-19.

30 Fadini GP, Boscaro E, Albiero M, Menegazzo L, Frison V, de Kreutzenberg S, et al. The oral dipeptidyl peptidase-4 inhibitor sitagliptin increases circulating endothelial progenitor cells in patients with type 2 diabetes: possible role of stromal-derived factor-1alpha. 

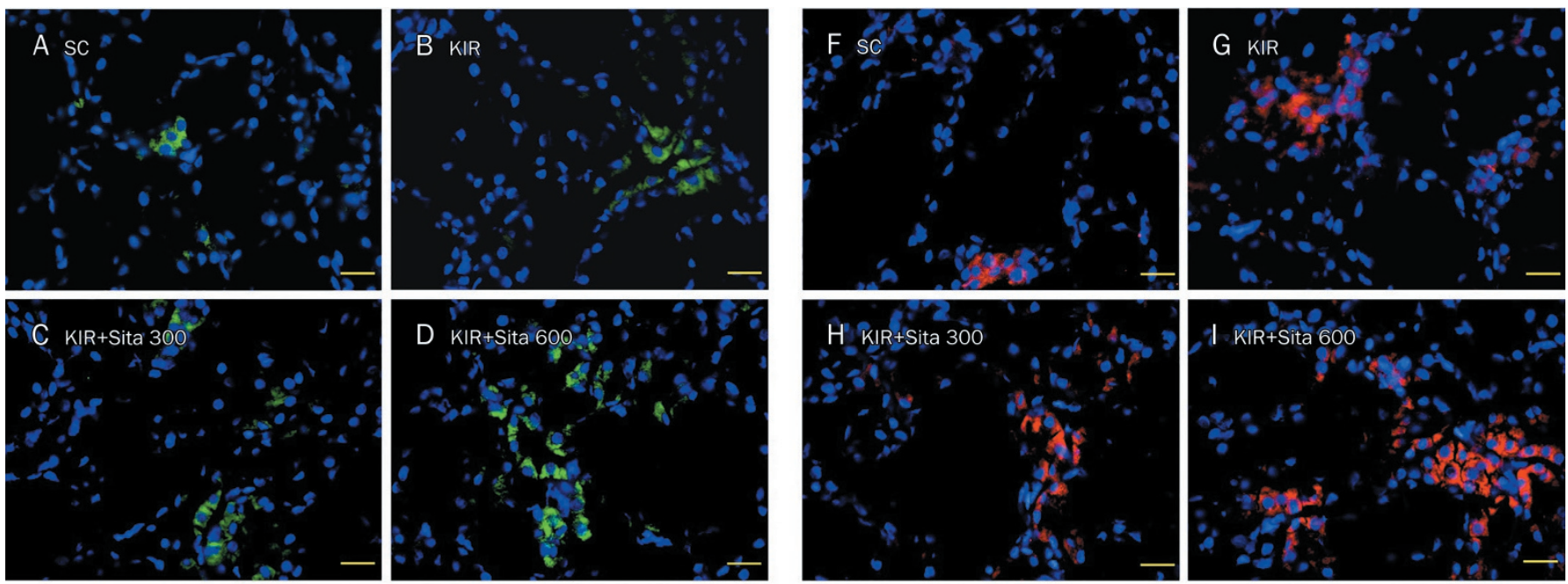

E

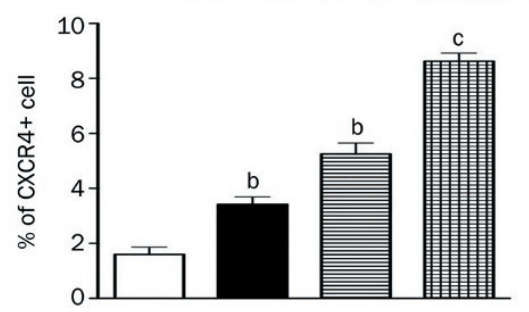

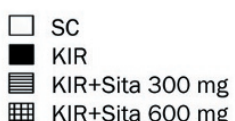

囲 KIR+Sita $600 \mathrm{mg}$
J

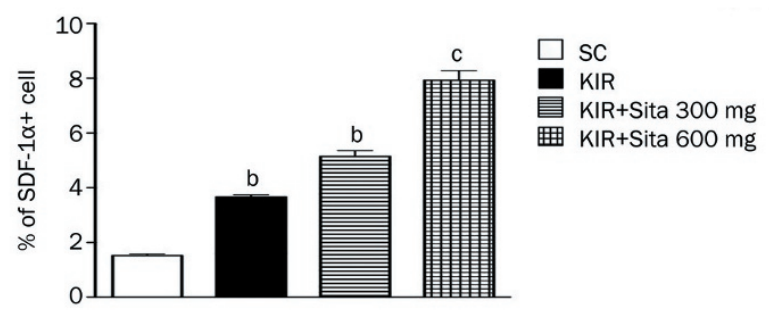

Figure 8. Angiogenesis cellular expression at $72 \mathrm{~h}$ after IR injury ( $n=8$ for each group). (A-D) IF microscopic findings (200x) showing the number of CXCR4+ cells in kidney parenchyma among four groups at $72 \mathrm{~h}$ after IR procedure. (E) The analytical results of CXCR4+ cells in kidney parenchyma at $72 \mathrm{~h}$ after IR procedure: ${ }^{\mathrm{c}} P<0.01$ vs sham control, ${ }^{\mathrm{b}} P=0.05$ vs other groups. (F-I) IF microscopic findings (200x) showing the number of stromal cell-derived factor SDF-1 $\alpha+$ cells in kidney parenchyma among four groups at $72 \mathrm{~h}$ after IR procedure. (J) The analytical results of SDF-1 $\alpha+$ cells in kidney parenchyma at $72 \mathrm{~h}$ after IR procedure: ${ }^{\mathrm{C}} P<0.01$ vs sham control, ${ }^{\mathrm{b}} P=0.05 \mathrm{vs}$ other groups. Scale bars in right lower corner represent $50 \mu \mathrm{m}$. All statistical analyses were with one-way ANOVA followed by Bonferroni multiple comparison post hoc test. SC, sham control; KIR, kidney ischemia reperfusion; Sita, sitagliptin.

Diabetes care 2010; 33: 1607-9.

31 Ishikawa S, Shimano M, Watarai M, Koyasu M, Uchikawa T, Ishii H, et al. Impact of sitagliptin on carotid intima-media thickness in patients with coronary artery disease and impaired glucose tolerance or mild diabetes mellitus. Am J Cardiol 2014; 114: 384-8.
32 McCormick LM, Kydd AC, Read PA, Ring LS, Bond SJ, Hoole SP, et al. Chronic dipeptidyl peptidase-4 inhibition with sitagliptin is associated with sustained protection against ischemic left ventricular dysfunction in a pilot study of patients with type 2 diabetes mellitus and coronary artery disease. Circ Cardiovasc Imaging 2014; 7: 274-81. 


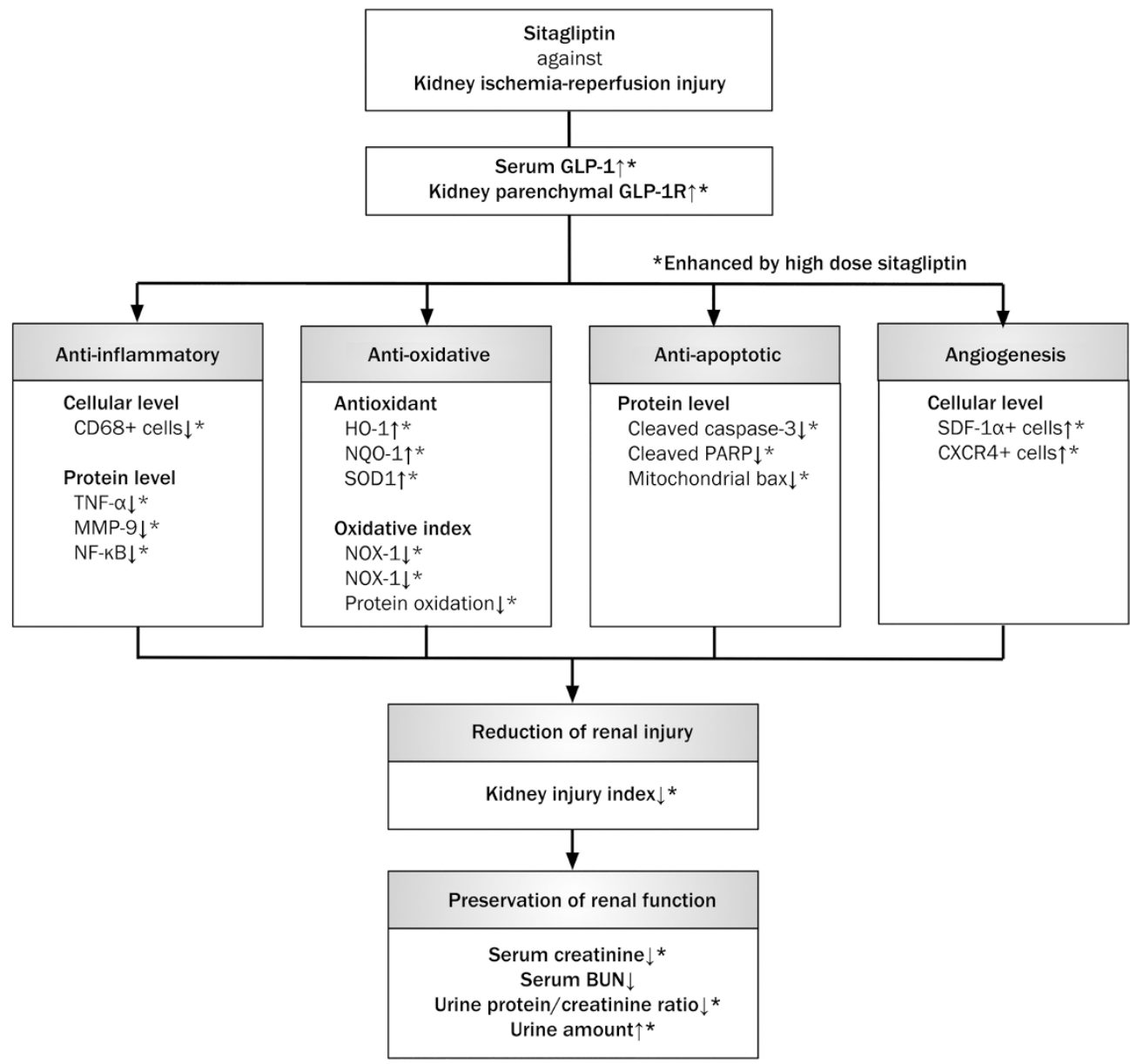

Figure 9. Proposed mechanisms underlying the positive therapeutic effects of sitagliptin and exendin-4 on kidney ischemia-reperfusion (IR) injury. GLP-1R, glycogen-like peptide-1 receptor; TNF, tumor necrotic factor; MMP, matrix metalloproteinase; NF, nuclear factor; HO, heme oxygenase; NQO, NAD(P)H quinone oxidoreductase; GR, glutathione reductase; GPx, glutathione peroxidase; NOX, ADPH oxidase; SOD, superoxide dismutase; PARP, poly(ADP-ribose) polymerase; BUN, blood urine nitrogen. 